Elsevier required licence: (C) <2018>. This manuscript version is made available under the CC-BY-NC-ND 4.0 license http://creativecommons.org/licenses/by-nc-nd/4.0/ 


\title{
Water Resource Selection and Optimisation for Shale Gas Developments in Australia: A Combinatorial Approach
}

\begin{abstract}
Australia has significant quantities of technically recoverable shale gas and the potential to become a major producer of natural gas from these unconventional resources. However, the hydrocarbon extraction process from shale formations involves heavy drilling and hydraulic fracturing. Both these activities consume a considerable volume of water, which impacts local communities and the environment. This paper proposes a combinatorial methodology that incorporates multi-criteria decision-making and system dynamics to select the best water resources, and then investigate the regional impact of consuming those resources over the longterm. The methodology is described through a case study on the Beetaloo Basin, Northern Territory - a prospective shale gas resources deposit. The results show that the produced water and fresh groundwater are appropriate options for the basin, and appropriate scenarios can prevent the over-extraction of fresh groundwater, maximise the reuse of water, and minimise aquifer disturbance. The proposed methodology is designed to support petroleum companies when making decisions about which water resources to use in shale mining operations to balance various factors affecting the system.
\end{abstract}

Keywords: shale gas, water management, MCDM, system dynamics.

\section{Introduction}

Australia has an estimated $11 \mathrm{Tcf}^{1}$ of contingent shale gas resources and $619 \mathrm{Tcf}$ of prospective resources (Geoscience Australia 2016). Developing these unconventional resources would contribute to growth in the country's energy market, but the shale gas industry in Australia is in its early stages, and additional exploratory activities are required to identify commercial reserves (Goldstein et al., 2012). In addition, regulatory, social, and environmental constraints are slowing the progress of these explorations (Cook et al., 2013). Overcoming these restrictions requires public acceptance, which could be achieved by maintaining a balance between the social, environmental, and economic aspects of the exploration and development phases of shale gas production (Rahm \& Riha, 2012). A critical subject of public debate is the extraction and use of water to develop shale gas fields (Vidic et al., 2013). Drilling and hydraulic fracturing activities demand a considerable volume of water over a relatively short period of time (Rahm \& Riha, 2012; Yang et al., 2014). Yet, consuming huge quantities of

\footnotetext{
${ }^{1}$ Trillion Cubic Feet
} 
water disturbs the environment and affects communities, particularly in locations with seasonal droughts and low stream flows (Soeder \& Kappel, 2009). This means petroleum companies must find reliable, inexpensive, and viable sources of water for their operations to minimise environmental impact and sustainably coexist with communities. By nature, these decisions are complicated as they involve various stakeholders, scientific studies, and subjective information (Linkov \& Moberg, 2011).

This paper proposes a methodology for selecting water resources for drilling and hydraulic fracturing during shale gas development. The methodology also demonstrates the long-term impact of consuming chosen water resources on the community and environment. As a typical example of a prospective shale deposit, the Beetaloo Basin in the Northern Territory, Australia has been chosen to demonstrate the proposed methodology in case study form. The methodology relies on a multi-criteria decision-making technique to determine the best water source(s) given technical, economic, social, and environmental factors. Then, the impact of using those water resources is simulated and analysed through system dynamics modelling. The factors explored include: the generation, availability, and consumption of water; its relationships with drilling and hydraulic fracturing activities; and the community and environmental impacts.

The methodology is intended to assist petroleum companies in evaluating a range of water resources for shale mining activities. The results provide valuable inputs for optimising water management plans to successfully develop these unconventional resources in a sustainable way and with public acceptance.

The rest of paper is organised as follows. Section 2 presents the literature review, followed by the proposed methodology in Section 3. Section 4 presents the case study and results. A discussion is provided in Section 5. Section 6 concludes the paper and suggests further research directions.

\section{Literature Review}

\subsection{Shale Gas Developments}

The hydrocarbons in shale resources are found in source rocks with very low permeability. Therefore, the oil and gas cannot naturally flow to the surface, and effectively exploiting shale gas requires a lengthening of the wellbore and artificially creating fractures in the rock formation (Jenkins \& Boyer, 2008). However, recent technological advancements in horizontal drilling and hydraulic fracturing have allowed the commercial development of shale resources. Horizontal drilling increases the contact area of the wellbore with the reservoir by laterally extending the length of the well. Hydraulic fracturing generates a network of conduits that 
increase permeability by injecting a high-pressure fracture fluid into the rock formation (DOE, 2009). Water is an essential component of typical fracture fluids and, together with a proppant (sand, treated sand, or ceramic material), it normally accounts for $98 \%$ of the fluid's composition. The rest is made up of chemical additives (Speight, 2013). To complete a well, hydraulic fracturing consumes approximately $90 \%$ of the total volume of water (Stark \& Thompson, 2013; Yang et al., 2014). The commercial development and production of shale gas resources requires hundreds or thousands of wells to be drilled and hydraulically fractured across a region and, consequently, immense quantities of water (DOE, 2009). Therefore, appropriately implementing water management plans is fundamental to sustainably procuring water, disposing of wastewater, and reducing the environmental and social impacts of shale gas development (Rahm \& Riha, 2012). Water management, in this context, incorporates four core components: selecting the water sources, preventing the over-extraction of fresh water, reusing and disposing of the water produced, and avoiding aquifer disturbance (Cook et al., 2013).

Improving water management through optimisation models in the shale gas industry has been studied in numerous papers. Many rely on mixed-integer linear programming to improve the water supply chain network and extend the water's lifecycle (Gao \& You, 2014; Yang et al., 2014). Although these optimisation models provide valuable information for efficiently administering water resources, they do not consider the environmental and social aspects of shale mining, which are very important for the public's acceptance of shale developments (Zarghami \& Szidarovszky, 2011). Therefore, when developing regionally appropriate solutions, it is critical to mitigate the impact of water consumption. This may include regulating water withdrawals, using brackish water instead of freshwater, and incorporating water recycling/reuse into policies (Jasmin et al., 2016). In addition, the long-term regional impacts of these policies need to be investigated.

The extant literature lacks a method for identifying the main factors that will affect communities and the environment when making decisions about which water resources to select. Further, appropriate models for analysing the long-term and widespread impacts of these decisions about shale mining operations are scarce.

\subsection{Multi-Criteria Decision Making}

Multi-criteria decision-making (MCDM) concerns decision making given multiple and conflicting criteria (Lu \& Ruan, 2007). It involves both quantitative and qualitative factors and numerous techniques for choosing the best, most feasible option. There are many forms of MCDM in the literature, e.g., multi-attribute utility theory (MAUT), techniques for ordering preferences by similarity according to ideal solutions (TOPSIS), the analytic hierarchy process 
(AHP), simple additive weighting (SAW), the simple multi-attribute rating technique (SMART), and so on. Our method relies on AHP, which derives ratio scales from paired comparisons in a multi-level hierarchy structure. The comparison values are either derived from actual measurements, or they are assigned from a fundamental scale that reflects relative preferences between a set of criteria and the available options. An AHP rating model comprises the following steps (Saaty, 2008):

Step 1: Develop a hierarchical structure for the research problem.

Step 2: Perform a pairwise comparison of the criteria and sub-criteria and generate comparison matrices using a fundamental scale of absolute numbers.

Step 3: Establish the rating categories for each criterion and sub-criterion and assign priorities to those categories from the pairwise comparisons. Generate comparison matrices for these categories also using a fundamental scale of absolute numbers. The ratings are expressed as idealised priorities in the ideal category with proportionate values allocated to the rest of the categories.

Step 4: Create a summary table for the prioritised rating categories of all criteria and subcriteria.

Step 5: Evaluate the alternatives by applying their respective assigned ratings to each of the criterion or sub-criterion to obtain the overall priorities and determine the best option.

\subsection{System Dynamics}

Systems dynamics (SD) is a methodology based on systems theory that studies the dynamic nature of complex feedback-driven systems (Cavana \& Maani, 2000). First, a conceptual and qualitative model is created to describe the causal processes operating in the system. Then, a quantitative model is structured and built for a computer simulation to show the nature and direction of the relationships within the system, so as to observe and understand its behaviour and responses over time. These models also help to visualise and analyse the effects of different intervention strategies (Winz et al., 2009). Cavana \& Maani (2000) point out the many advantages of SD modelling. First, such models reveal the nature of relationships using causal loop diagrams and stock flow diagrams. Second, these models include both linear and nonlinear relationships. Third, policy issues can be measured to help decision making. Table 1 summarises the SD phases along with steps required in each phase; however, all steps are not necessary for every project. 
Table 1: Summary of the SD modelling process (Cavana \& Maani 2000).

\begin{tabular}{|c|c|}
\hline Phases & Steps \\
\hline 1. Problem structuring & $\begin{array}{l}\text { 1- Identify problems or issues of concern to management } \\
\text { 2- Collect preliminary information and data }\end{array}$ \\
\hline 2. Casual loop modelling & $\begin{array}{l}\text { 1- } \text { Identify the main variables } \\
\text { 2- } \quad \text { Prepare behaviour over time graphs } \\
\text { 3- } \quad \text { Develop causal loop diagrams } \\
\text { 4- Analyse loop behaviour over time } \\
\text { 5- Identify system archetypes } \\
\text { 6- Identify key leverage points } \\
\text { 7- } \quad \text { Develop intervention strategies }\end{array}$ \\
\hline 3. Dynamic modelling & 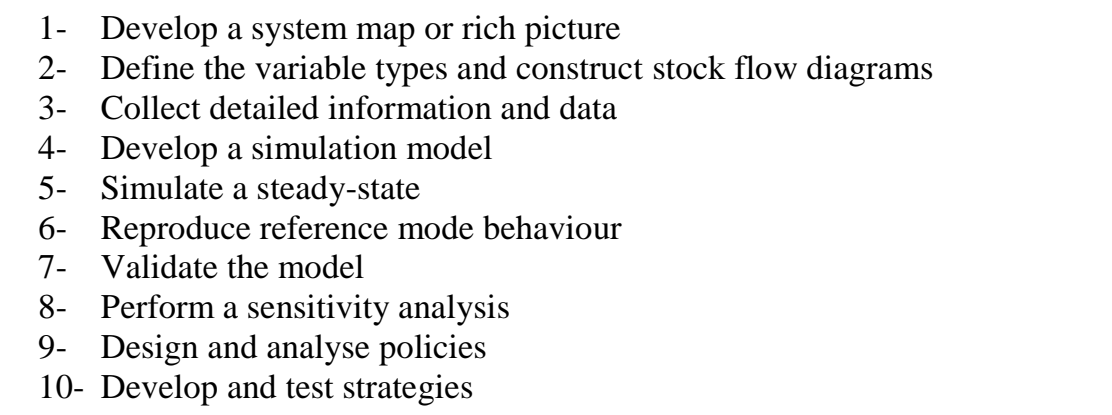 \\
\hline 4. Scenario planning & $\begin{array}{l}\text { 1- Plan the general scope of scenarios } \\
\text { 2- Identify key drivers of change and uncertainties } \\
\text { 3- } \text { Construct forced scenarios and learning scenarios } \\
\text { 4- Simulate scenarios within the model } \\
\text { 5- Evaluate the robustness of policies and strategies }\end{array}$ \\
\hline $\begin{array}{l}\text { 5. Implementation and } \\
\text { organisational learning }\end{array}$ & $\begin{array}{l}\text { 1- Prepare a report for the management team } \\
\text { 2- Communicate the results and insights of the intervention to stakeholders } \\
\text { 3- Develop a micro-world and learning lab based on the simulation model } \\
\text { 4- Use the learning lab to examine mental models }\end{array}$ \\
\hline
\end{tabular}

\section{Methodology}

The methodology proposed in this section can be applied to any basin with prospective shale resources or during the development of an existing shale gas play. The main results are: the optimal sources of water, the key variables of the system, and the degree of adjustments needed to these variables to balance technical, economic, social, and environmental factors. The methodology consists of three phases as detailed in Figure 1. 


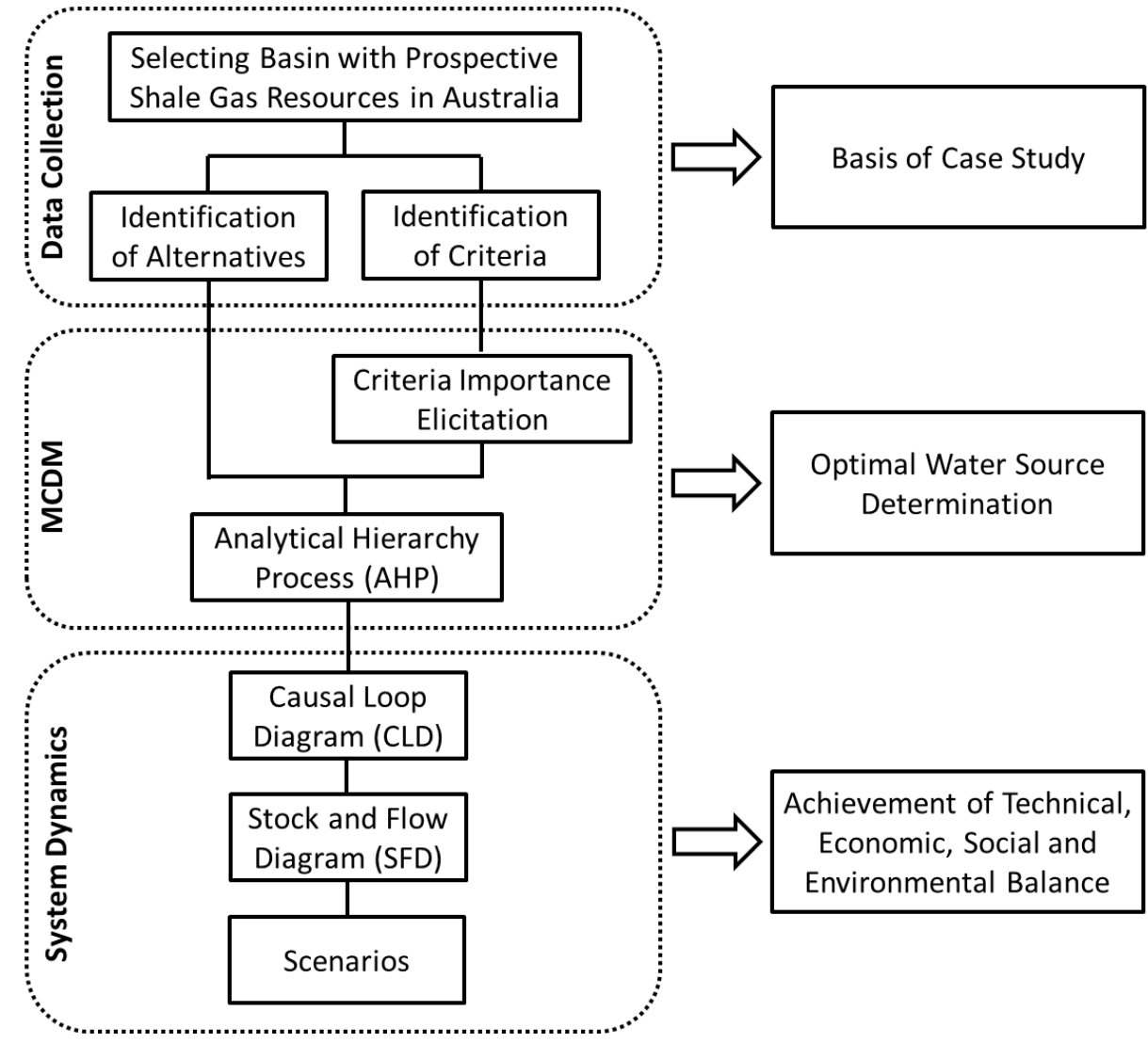

Figure 1: The proposed methodology.

\subsection{Phase 1: Data Collection}

In Phase 1, sufficient information from the basin of study about the shale gas development and its regional water characteristics is acquired to effectively apply the methodology. The main components of MCDM are the decision-makers, stakeholders, alternatives, and criteria, which are distinct to each region. Typically, petroleum companies are the decision-makers, and the community, the government, and other regional industries are the primary stakeholders. The available sources of water in the shale gas development area are the alternatives. The technical, economic, social, and environmental aspects form the criteria. Identifying and understanding the alternative water sources, the selection criteria, and the factors that form each criterion are critical before proceeding to the next phase.

Identifying the alternatives: The available and feasible water sources are identified in the basin as they constitute the alternatives of the MCDM. The principal sources of water for shale gas development are surface water from rivers and lakes, groundwater from fresh, brackish or saline aquifers, produced water from the production flow of other shale gas wells, and unorthodox sources, such as residual coal mine water or seawater (Horner et al., 2016; Rahm $\&$ Riha, 2012). The ability to reuse produced water for hydraulically fracturing subsequent wells is crucial to every study because it significantly reduces potable water requirements. 
However, the contamination and availability of produced water could restrict its reuse (Cook et al., 2013).

Identifying the criteria: The technical, economic, social, and environmental aspects are toplevel criteria, but it is essential to identify the major factors or sub-criteria that form each main criterion. Generally, technical and economic criteria are objective, quantitative attributes, while social and environmental criteria are subjective and qualitative. Although this study focuses on these four aspects, further main criteria could be included in any evaluation.

\subsection{Phase 2: MCDM}

In Phase 2, weights are assigned to the criteria and sub-criteria, and the most appropriate water sources are determined using AHP. The relative importance of each criteria and sub-criterion is obtained through consultation with expert(s). If more than one expert is involved, it would be a group MCDM. The AHP rating model described by Saaty (2008) derives the priorities for the alternatives and criteria.

\subsection{Phase 3: System Dynamics}

The impact of decision-making results from the previous phase are evaluated using SD modelling. Furthermore, this process identifies the main variables of a system so they can be corrected and regulated to achieve a desired balance between the technical, economic, social, and environmental factors. The methodology incorporates the procedure described by Cavana \& Maani (2000). A casual loop diagram (CLD) is constructed to graphically model the system by showing the components and their relationships as a collection of connected cause and effect variables and feedback loops. The principal variables are the water sources selected through the MCDM phase. The CLD is converted into a stock flow diagram (SFD), and constants, equations, and initial values are assigned to the variables. The behaviour of the system and different scenarios are investigated through simulations. The aim is to recognise the controllable and uncontrollable variables that can assist in regulating the system to achieve an accepted behaviour.

\section{Case Study: Beetaloo Basin in Northern Territory}

The Beetaloo Basin in Northern Territory (NT) was selected as a case study because it has considerable shale gas resources and a high probability of near-future development. The NT has an estimated $231 \mathrm{Tcf}$ of shale gas resources, and approximately $70 \%$ of these resources are located in the Beetaloo Basin (Geoscience Australia 2016). As shown in Figure 2, the Beetaloo Basin is situated in the Sturt Plateau region, between the towns of Mataranka and Elliot, and covers an area of approximately $30,000 \mathrm{~km}^{2}$ (Hart et al. 2017). 


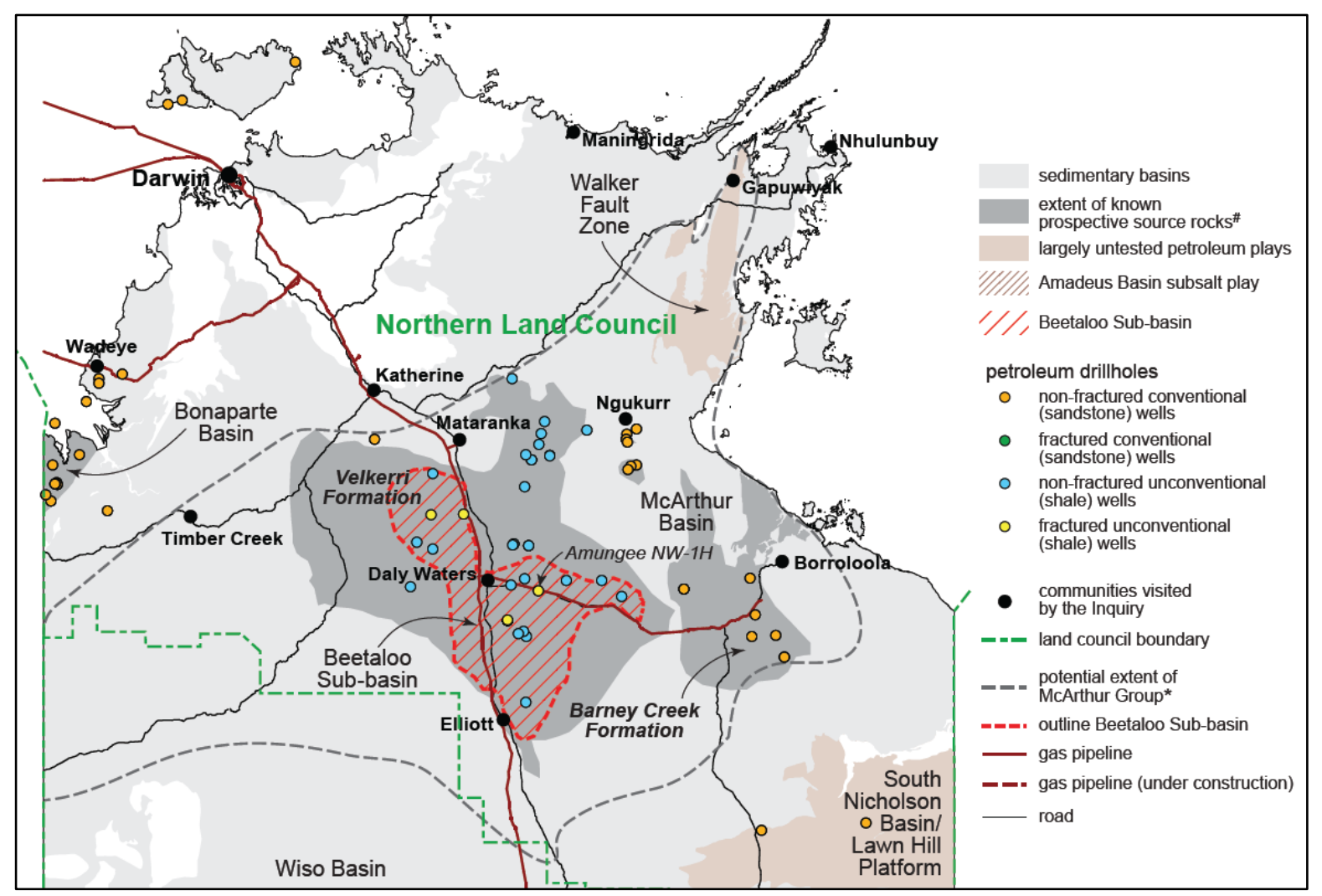

Figure 2: Petroleum wells in the Beetaloo Basin.

\subsection{Water Sources}

The climate in NT is highly affected by seasonal rainfalls. Its ecosystems range from tropical regions in the north to arid or semi-arid in the central and southern regions (Hart et al. 2017). The summer monsoon dominates rainfall in the Beetaloo Basin. During this season, aquifers are recharged, surface streams refreshed, and flood-lands are inundated. There are no permanent surface water sources in the Beetaloo Basin; hence, rivers, streams, lakes, and waterholes are only available for short periods and depend on wet season rains (Cook et al., 2013). An estimated $90 \%$ of the total rainfall evaporates, and less than $2 \%$ enters the groundwater system (Hart et al. 2017). In the northern, tropical part of the region, most of the aquifers are recharged during the wet season, which results in very low salinity. In the arid and semi-arid areas, recharging is minimal, resulting in reduced water quality and almost nonexistent sources of surface water. Groundwater constitutes $90 \%$ of the water supply in NT.

\subsection{Criteria and Sub-criteria}

The assessment task is a complex multi-criteria decision-making problem. Selecting appropriate source(s) of shale gas water requires that some underlying criteria for making the choice are identified, but that is a difficult task because there is no one solid answer. Moreover, it is not absolute that increasing the number of the criteria will be helpful for making a decision. 
In fact, sometimes fewer criteria may be more beneficial, especially if it means reducing redundancy in the criteria system (Wang et al., 2009). In this study, we developed an evaluation criteria system with four criteria - technical, economic, social, and environmental - and nine sub-criteria spanning to assess the alternatives, as shown in Table 2. These criteria and subcriteria were drawn from our review of the literature (Cook et al., 2013) (Hart et al., 2017) (Warner, 2011) (Horner et al. 2016) (DOE 2009) (Nevill et al. 2010) (Rahm \& Riha 2012) and from focus groups with experts with at least five years of professional experience in the oil and gas industry.

Table 2: Criteria and sub-criteria

\begin{tabular}{ll}
\hline Criteria & Sub-criteria \\
\hline Technical & Water availability \\
Economic & Water withdrawal cost \\
& Transportation cost \\
& Treatment cost \\
Social & Potable water depletion \\
& Competition for water \\
& Landscape damage \\
Environmental & Water consumption \\
& Flow regimes disruption \\
\hline
\end{tabular}

\subsection{AHP Results}

According to the expert, all criteria play an equally important role in the decision-making problem. Therefore, pairwise comparisons at the criteria level were not required. Instead, we began with the sub-criteria level. Table 3, for example, shows the results of pairwise comparisons for the social criteria. The criteria and sub-criteria priorities (weights) are summarised in Table 4. The other matrices have been omitted due to space limitations.

Table 3: The pairwise comparison matrix for the social sub-criteria.

\begin{tabular}{lcccc}
\hline & Potable water depletion & Competition for water & Landscape damage & Priority \\
\hline Potable water depletion & 1.000 & 3.000 & 7.000 & 0.676 \\
Competition for water & 0.333 & 1.000 & 4.000 & 0.237 \\
Landscape damage & 0.143 & 0.250 & 1.000 & 0.087 \\
\hline
\end{tabular}


Table 4: The criteria and sub-criteria priorities.

\begin{tabular}{lclc}
\hline Criteria & Priority & Sub-criteria & Priority \\
\hline Technical & {$[0.250]$} & Water availability & {$[1.000]$} \\
Economic & {$[0.250]$} & Water withdrawal cost & {$[0.631]$} \\
& & Transportation cost & {$[0.224]$} \\
& & Treatment cost & {$[0.145]$} \\
Social & {$[0.250]$} & Potable water depletion & {$[0.676]$} \\
& & Competition for water & {$[0.237]$} \\
& & Landscape damage & {$[0.087]$} \\
Environmental & {$[0.250]$} & Water consumption & {$[0.545]$} \\
& & Flow regimes disruption & {$[0.455]$} \\
\hline
\end{tabular}

Each alternative was evaluated by applying the inferred rating values to each criterion and subcriterion. Table 5 shows the final results of the AHP. The results indicate that produced water has the highest priority as a source water source. However, to formulate fracture fluid, this source requires treatment and fresh water; salts, total dissolved solids, and contaminants must be diluted (Vidic et al., 2013). Thus, both produced water and fresh groundwater are appropriate options for the Beetaloo Basin.

Table 5: The AHP results.

\begin{tabular}{lcc}
\hline Alternatives & Overall priority & Normalised priority \\
\hline Surface water & 0.434 & 0.174 \\
Fresh groundwater & 0.653 & 0.262 \\
Brackish/saline groundwater & 0.696 & 0.279 \\
Produced water & 0.711 & 0.285 \\
\hline
\end{tabular}

\subsection{System Dynamics Models}

The system dynamics modelling focused on the two selected water sources obtained from the AHP analysis. The aim of problem structuring is to apply systems thinking to holistically identify the multiple interconnected elements that relate to the technical, economic, social, and environmental factors of water source use. The information obtained from Phase 1 was primarily used to structure the problem and establish the major elements that affect the system.

\subsubsection{Causal Loop Modelling}

Figure 4 shows a CLD for the use of fresh groundwater and produced water in shale gas developments in Beetaloo Basin. The shaded area represents the technical aspects of the system that ultimately impact social and environmental factors. The scale of the development determines the number of wells to be drilled and fractured over a period of time, and the water 
requirements are estimated accordingly. The optimal water sources in the Beetaloo Basin, i.e., produced water and fresh groundwater, each have different social and environmental consequences. Produced water is generated from water returned to the surface after hydraulic fracturing operations, and a specific treatment is required before it can be recycled and reused. An increase in the consumption of treated water causes a decrease in the consumption of fresh groundwater. Consequently, this leads to a reduction in the competition for fresh water with the community and other industries, which results in less environmental impact and greater public acceptance.

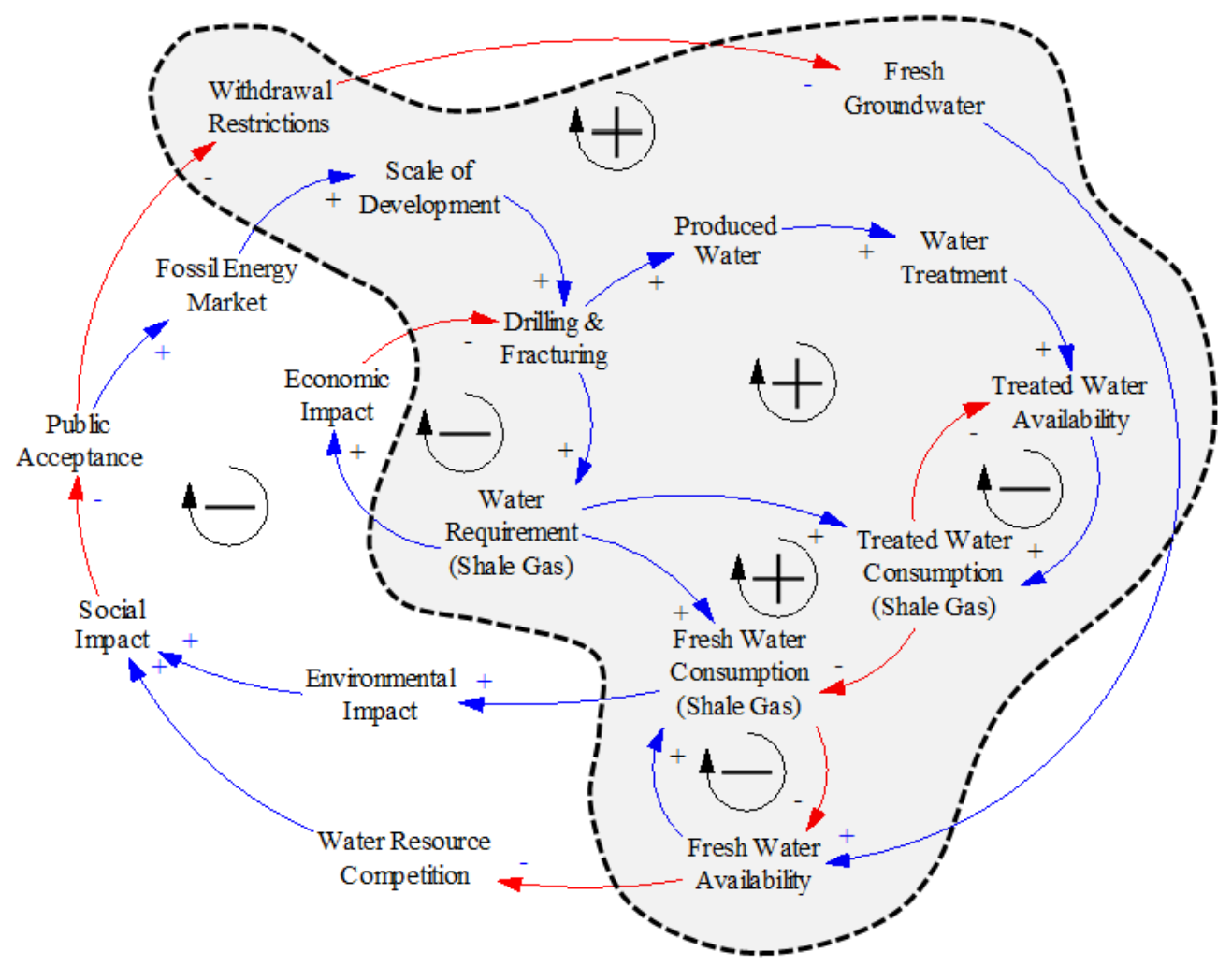

Figure 3: The CLD of fresh groundwater and produced water usage.

Conversely, if the produced water has a low quality with high concentrations of total dissolved solids and impurities that affect fracture fluid formulation, or there is insufficient flowback to the surface after hydraulic fracturing, or the cost of the treatment is unacceptable, less treated water would be available, which would increase the use of fresh groundwater water and trigger negative environmental and societal effects. Reduced public acceptance may, in turn, cause restrictions to procuring fresh groundwater, leading to scarcity that would affect development.

\subsubsection{Dynamic Modelling}

Water requirements, availability, and consumption constitute the technical factors of the case study, which are critical to achieving the desired economic, social, and environmental balance. 
These technical aspects were input into the SD model to construct the SFD and run simulations. The shaded area in the CLD in Figure 4 represents the technical aspects of the system that were converted into the SFD shown in Figure 5.

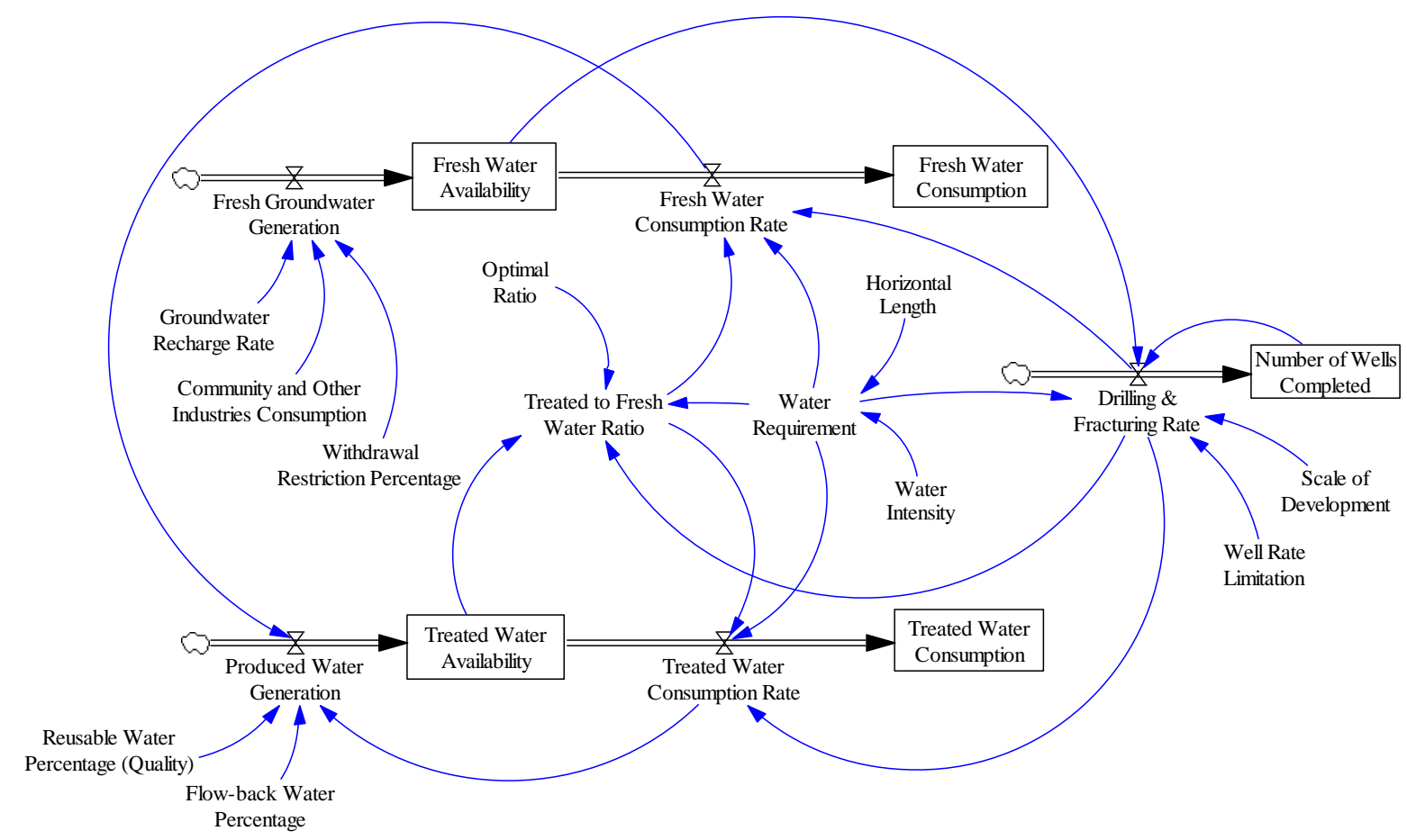

Figure 4: The SFD of the technical aspects.

An auxiliary variable, the water requirement, is critical for determining the drilling and fracturing rate, the consumption rates, and the treated-to-fresh water ratio. The water requirement is calculated from the horizontal length and the water intensity of the wells, which are both related to advancements in technology and the geological characteristics of the formation. The scale of development, the availability of rigs in the area, and the volume of fresh water determine the crucial flow variable of the drilling and fracturing rate, which subsequently feeds the stock variable of the total number of wells completed over time. The drilling and fracturing rate is used together with the water requirement and the treated-to-fresh water ratio to define the flow variables of fresh groundwater and treated water consumption rates. The treated-to-fresh water ratio calculation depends on the availability of treated water. The aim is to maintain an optimal reuse ratio, which is calculated depending on the necessary volumes of fresh water to dilute the treated water with total dissolved solids and impurities. The flow variable of fresh groundwater generation depends on: the recharge rate of the aquifers from rainfall; the withdrawal restrictions imposed by the government, community or environmental concerns; and the consumption of groundwater from the local population and other industries. The recharge rate has been identified as a major uncontrollable auxiliary variable, as it varies significantly and affects the overall system. A sine function was used to 
address these variances and observe system behaviour. However, the flow variable for produced water generation was derived by summing the fresh groundwater and treated water consumption rates. It also considers the quality limitations to recycling and reusing produced water and the recovery volume of flowback water at the surface. The stock variables of fresh groundwater and treated water availability are calculated from the difference between the respective generation and consumptions rates. Finally, the consumption rates of each water source are accumulated in stock variables to calculate the total amount of water consumption.

The base case to visualise and understand the reference mode behaviour is based on factual values and the averages obtained from the research and data collection undertaken in Phase 1. The assigned constants, equations, and initial values of the flow, stock and auxiliary variables are shown in Table 6.

Table 6: The equations, values, and units for the variables in the SFD.

\begin{tabular}{|c|c|c|c|c|c|}
\hline Name & \multicolumn{2}{|c|}{ Type } & \multirow{2}{*}{\begin{tabular}{c|} 
Units \\
ML/Year
\end{tabular}} & \multirow{2}{*}{$\begin{array}{l}\text { Initial } \\
\text { Value } \\
\end{array}$} & Equation \\
\hline Fresh Groundwater Generation & Variable & Flow & & & $\begin{array}{l}\text { (Groundwater Recharge } \\
\text { Rate+15000*SIN }(x))^{*} \text { Withdrawal Restriction } \\
\text { Percentage-Community and Other Industries } \\
\text { Consumption }\end{array}$ \\
\hline Groundwater Recharge Rate & Constant & Auxiliary & ML/Year & & 115000 \\
\hline $\begin{array}{l}\text { Community and Other Industries } \\
\text { Consumption }\end{array}$ & Constant & Auxiliary & ML/Year & & 14000 \\
\hline Withdrawal Restriction Percentage & Constant & Auxiliary & Dmnl & & 0.2 \\
\hline Fresh Water Availability & Variable & Stock & ML & 3250 & $\begin{array}{l}\text { IF THEN ELSE(Fresh Water Availability<0, } 0 \text {, } \\
\text { Fresh Groundwater Generation-Fresh Water } \\
\text { Consumption Rate) }\end{array}$ \\
\hline Fresh Water Consumption Rate & Variable & Flow & ML/Year & & $\begin{array}{l}\text { Water Requirement }{ }^{\star}(1-\text { Treated-to-fresh Water } \\
\text { Ratio })^{\star} \text { Drilling \& Fracturing Rate }\end{array}$ \\
\hline Fresh Water Consumption & Variable & Stock & $\mathrm{ML}$ & 0 & Fresh Water Consumption Rate \\
\hline Drilling \& Fracturing Rate & Variable & Flow & Well/Year & & $\begin{array}{l}\text { IF THEN ELSE(Number of Wells } \\
\text { Completed>Scale of Development, 0, IF THEN } \\
\text { ELSE(Fresh Water Availability>Water } \\
\text { Requirement*Well Rate Limitation, Well Rate } \\
\text { Limitation, Fresh Water Availability/Water } \\
\text { Requirement)) }\end{array}$ \\
\hline Scale of Development & Constant & Auxiliary & Well & & 6250 \\
\hline Well Rate Limitation & Constant & Auxiliary & Well/Year & & 312.5 \\
\hline Number of Wells Completed & Variable & Stock & Well & 0 & Drilling \& Fracturing Rate \\
\hline Water Requirement & Variable & Auxiliary & ML/Well & & (1.5+Horizontal Length*Water Intensity) \\
\hline Horizontal Length & Constant & Auxiliary & $\mathrm{m} /$ Well & & 1350 \\
\hline Water Intensity & Constant & Auxiliary & $\mathrm{ML} / \mathrm{m}$ & & 0.01175 \\
\hline Treated-to-fresh Water Ratio & Variable & Auxiliary & Dmnl & & $\begin{array}{l}\text { IF THEN ELSE(Optimal Ratio*Water } \\
\text { Requirement*Drilling \& Fracturing Rate }<\text { Treated } \\
\text { Water Availability, Optimal Ratio,(Treated Water } \\
\text { Availability*Optimal Ratio)/(Optimal Ratio*Water } \\
\text { Requirement*"Drilling \& Fracturing Rate")) } \\
\end{array}$ \\
\hline Optimal Ratio & Constant & Auxiliary & Dmnl & & 0.2 \\
\hline Produced Water Generation & Variable & Flow & $\mathrm{ML} /$ Year & & $\begin{array}{l}\text { (Fresh Water Consumption Rate+Treated Water } \\
\text { Consumption Rate)* Reusable Water Percentage } \\
\text { (Quality) }{ }^{\star} \text { Flowback Water Percentage }\end{array}$ \\
\hline $\begin{array}{l}\text { Reusable Water Percentage } \\
\text { (Quality) }\end{array}$ & Constant & Auxiliary & Dmnl & & 0.45 \\
\hline Flowback Water Percentage & Constant & Auxiliary & Dmnl & & 0.3 \\
\hline Treated Water Availability & Variable & Stock & ML & 0 & $\begin{array}{l}\text { Produced Water Generation-Treated Water } \\
\text { Consumption Rate }\end{array}$ \\
\hline Treated Water Consumption Rate & Variable & Flow & $\mathrm{ML} /$ Year & & $\begin{array}{l}\text { Water Requirement*Treated-to-fresh Water } \\
\text { Ratio*Drilling \& Fracturing Rate }\end{array}$ \\
\hline Treated Water Consumption & Variable & Stock & $\mathrm{ML}$ & 0 & Treated Water Consumption Rate \\
\hline
\end{tabular}


The reference mode graphs of the major variables of the systems are shown in Figure 6. The simulation was run as a time lapse of 40 years, which is the maximum development period estimated by NT DPIR (Hart et al. 2017).

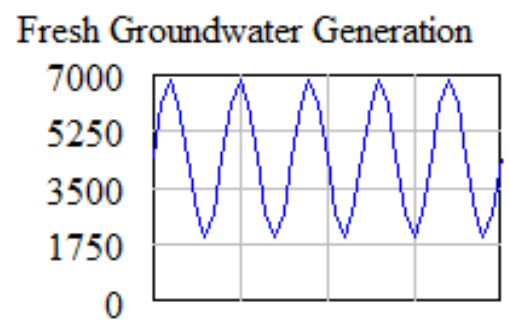

Fresh Water Availability

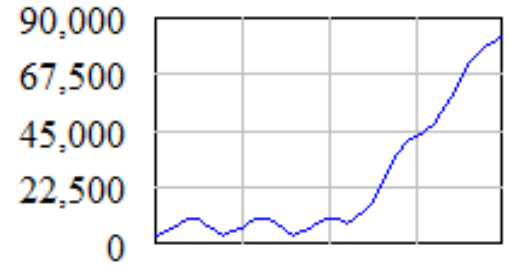

Fresh Water Consumption Rate

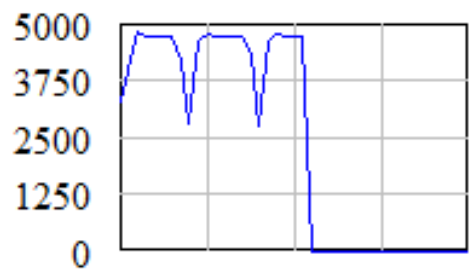

Fresh Water Consumption

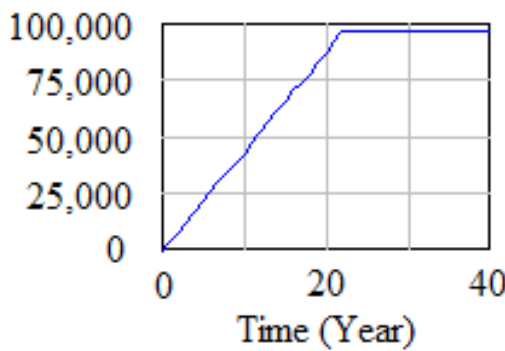

Produced Water Generation

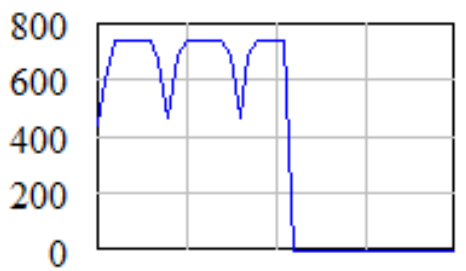

Treated Water Availability

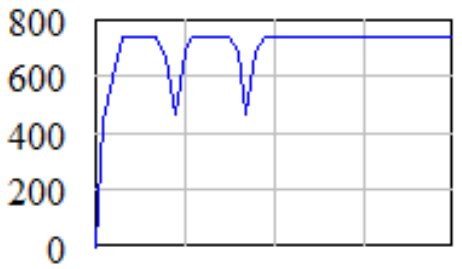

Treated Water Consumption Rate Water Requirement

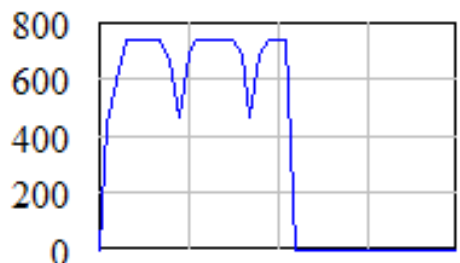

Treated Water Consumption

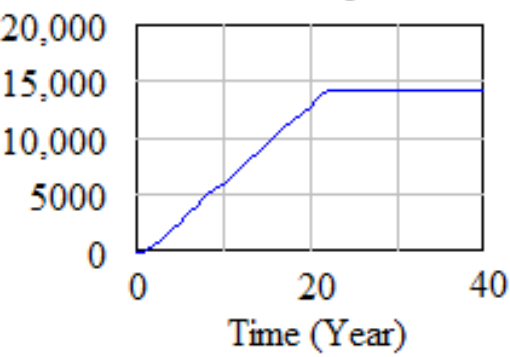

10
"Drilling \& Fracturing Rate"

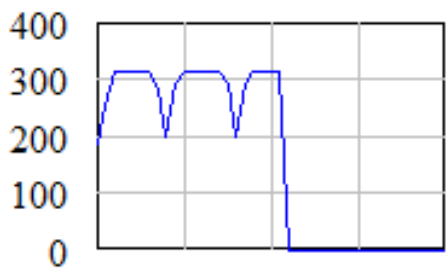

Treated to Fresh Water Ratio

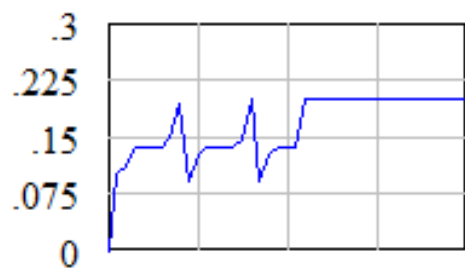

Number of Wells Completed

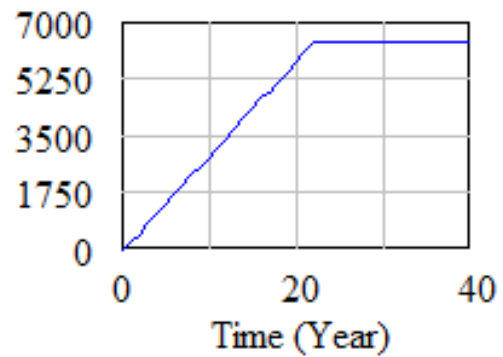

Figure 5: System dynamics graphs of the technical aspects of the system.

Accumulated fresh groundwater is used almost entirely during the shale gas development because there is insufficient fresh water to maintain the maximum possible drilling and fracturing rate of 312.5 wells per year. This value comes from limitations in the well rate, and represents the number of rigs available in the area. The system will compensate for the variations in fresh water generation by regulating the treated-to-fresh water ratio to maximise the use of treated water. This control system tries to maintain a ratio of 0.2 , but it is only achieved momentarily when the groundwater recharge rate affecting the freshwater generation reaches the peak of the sine function $(7000 \mathrm{ML} / \mathrm{year})$. At this stage, the stock of available fresh water is able to accumulate approximately 10,000 ML, which immediately triggers an increase in the drilling and fracturing rate to the maximum limit and consumes the fresh water again. 
Treated water is always available and is adjusted depending on the drilling and fracturing rate changes from fresh water generation and availability. The time to complete the total number of wells is adjusted accordingly. In this case, given the above restrictions, the shale gas development of 6250 wells is completed in 22 years. It consumes a total of 96,406 ML of fresh water and 14,199 ML of reused produced water.

\subsubsection{SD Model Testing}

We used both verification and validation to test the SD model (Pruyt, 2013). Model verification means testing whether the model has been coded correctly and therefore simulates operations accurately. The equations were reviewed to ensure they were correct and coded properly, and the consistency of the units was double checked. Model validation includes a range of tests to determine whether a model meets the objectives of the study. The first test examines steadystate behaviour by setting all the inflows for the stock variables, i.e., the availability of both fresh and treated water as equal to the outflows. Further, we performed some direct structure tests to ensure the bounds were adequate and that the structure represented a realistic system and conformed to the laws of nature. We also checked that the structures and parameters had real-world counterparts and were consistent with our knowledge of the system. The industry expert further assessed the model structures and equations as appropriate for the intended purpose.

As SD models contain some uncertain variables, we also used a sensitivity analysis to validate the system. A sensitivity analysis examines the effect of relatively small changes to the parameter values on behaviour (behavioural sensitivity), or changes in preference for a particular policy (policy sensitivity) starting from a base case (Pruyt, 2013). The next section presents these behavioural and policy sensitivity analyses along with a description of the scenario planning.

\subsubsection{Scenario Planning}

This section describes the key variables used in both the sensitivity analysis and the scenario planning to understand the behaviour of the system under different circumstances.

Scenario 1: The Beetaloo Basin is in the early stages of exploration, so reliable data is scarce. This results in a high level of uncertainty in the variables that directly impact produced water generation and availability, such as produced water quality, flowback recovery rate, and optimally treated-to-fresh water ratios. These variables are uncontrollable. They basically depend on the geological properties of the shale formation and, to some extent, the design of the wells. The values assigned to these variables were based on assumptions made from the US analogues of comparable shale plays but, in some instances, the range was very broad. As an 
example, the produced water recovery rates in the Marcellus shale have low recovery rates in the range of $7-25 \%$, while the Barnett field presents recovery rates above $75 \%$ of the injected water from hydraulic stimulation (Rahm \& Riha, 2012; Stark \& Thompson, 2013). Produced water generation is an integral and essential part of the system that may reflect the level of success in water management during the development. Figure 7 shows the modelling results of the sensitivity analysis for Scenario 1 for variations in produced water generation created by the modification of the flowback water percentage.
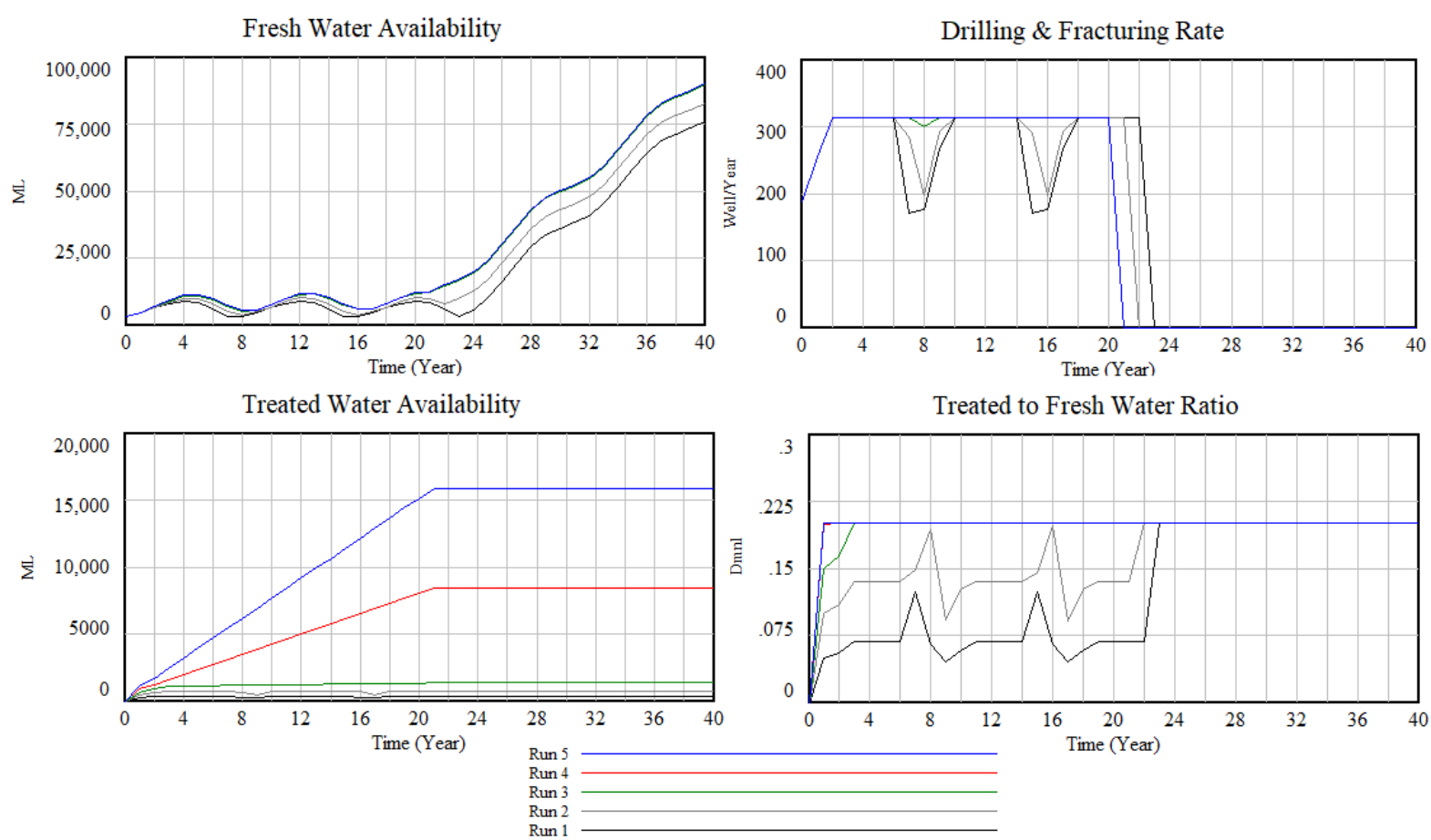

Figure 6: Scenario 1- Variations in produced water generation.

The simulation comprised five runs with varied flowback recovery in increasing steps of $15 \%$, from $15 \%$ in run 1 to $75 \%$ in run 5 . The results demonstrate that treated water availability increased with higher flowback recovery rates, but once the flowback water recovery percentage reached $45 \%$, there was insufficient fresh water in the system to use the additional treated water available because of the ratio required to formulate the fracture fluid. This results in an accumulation of treated water. Therefore, given these parameters, there is no extra benefit in a return rate higher than $45 \%$ because the groundwater recharge rate is insufficient to completely use the rest of the treated water. On the contrary, an excess of treated water generates the problem of wastewater management because the treated water cannot be reincorporated into the environment. Advanced treatment to further decontaminate the water would be required for that. Further, the results also show that the time of field development reduces by approximately one year for every $15 \%$ increase in the flowback water recovery 
percentage up to the $45 \%$ mark. Moreover, there is a saving of almost $14,000 \mathrm{ML}$ of fresh water when compared to the produced water recovery percentage of $15 \%$ to $45 \%$ or above.

Scenario 2: The second scenario that was simulated involved variations in the water requirement through horizontal length and water intensity. These are controllable variables that directly affect the production of natural gas. More extensive horizontal sections of the well create a higher contact area in the wellbore with a reservoir to perform multi-stage hydraulic fracturing. However, the maximum achievable length is limited by currently available drilling technology, and it increases operational risk. Higher water intensity allows an increase in the volume of rock that is fractured, but its extension is adjusted to avoid interference with the adjacent fracturing stages. A study by Nicot and Scanlon (2012) shows that the major US shale plays have water intensities in the range of 0.0095-0.014 ML per metre of the productive lateral section of a well. Figure 8 shows the graphs generated from the Scenario 2 simulations.
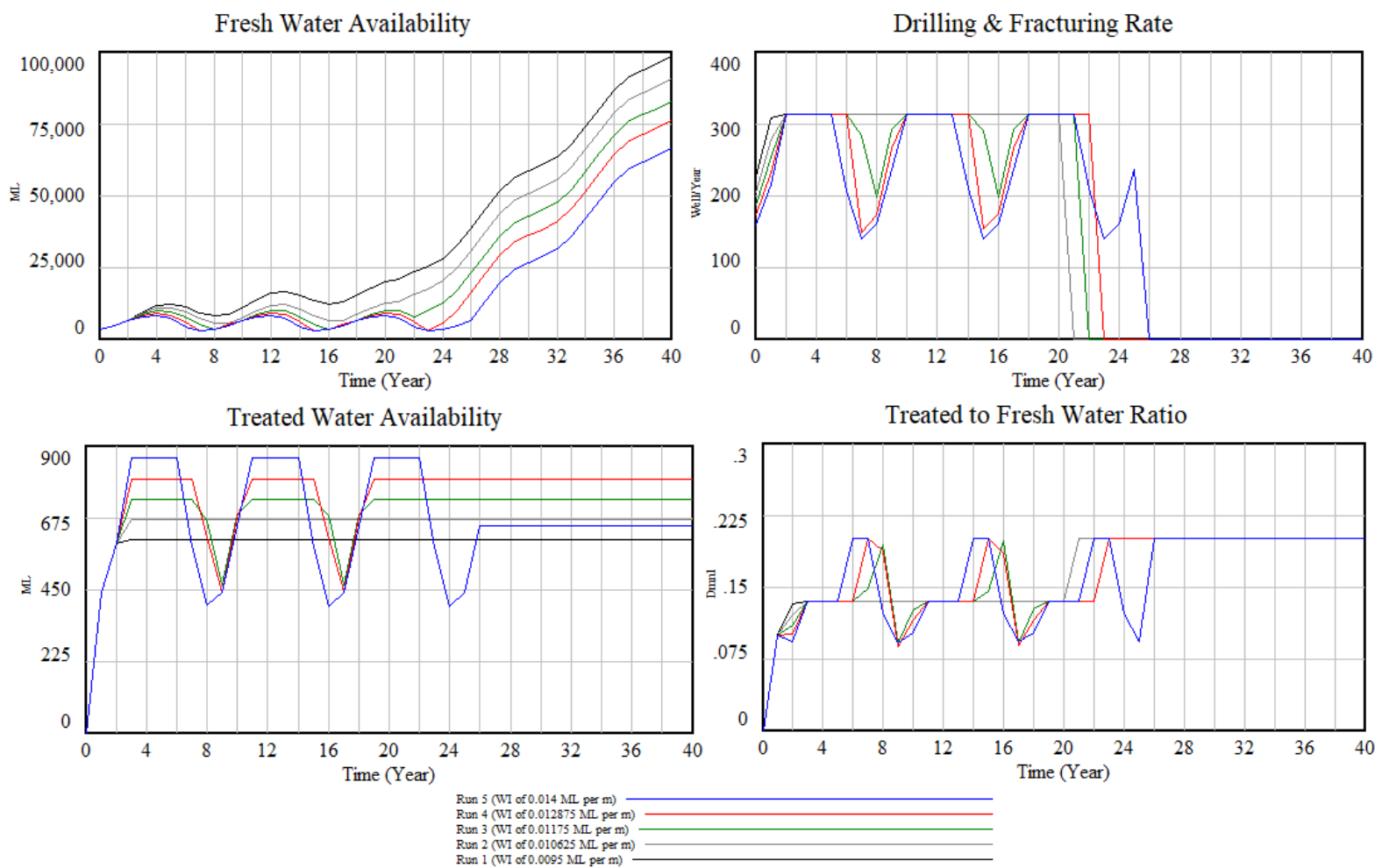

Figure 7: Scenario 2-Variation of water requirements.

The model incorporated the specified water intensity range, starting with run 1 at $0.0095 \mathrm{ML} / \mathrm{m}$ increasing incrementally in subsequent runs by $0.001125 \mathrm{ML} / \mathrm{m}$ until run 5 at $0.014 \mathrm{ML} / \mathrm{m}$. Water requirements changed considerably between $14.325 \mathrm{ML} /$ well to $20.4 \mathrm{ML} /$ well when modifying the water intensity value along the selected range. The time of development for 6250 wells moves to between 21 and 26 years. An interesting result is that in runs 1 and 2, the use of treated water was not affected by oscillations in the groundwater recharge rate because sufficient fresh water is available, but there is insufficient treated water. This effect can be 
interpreted through the treated-to-fresh water ratio. Consequently, in these two scenarios, there is an accumulation of fresh water in the aquifers from the beginning of development that surpasses the oscillatory base consumption of fresh water. In contrast, the other runs with higher water intensities consumed all the available fresh water and maximised the use of treated water depending on freshwater availability until the development was complete.

\section{Discussion}

The AHP results show that the most appropriate water source for shale gas development in the Beetaloo Basin is produced water, followed by brackish/saline groundwater, then fresh groundwater, with the worst option being surface water. The difference in the priority rankings between the produced water and the brackish/saline groundwater with the assigned ratings is minimal. Hence, a sensitivity analysis was performed to corroborate the results by altering the values with the highest degree of uncertainty, which are the characteristics associated with produced water availability. Produced water is obtained from reusable flowback water after hydraulic fracturing. The amount varies significantly and depends on the shale formation and well design.

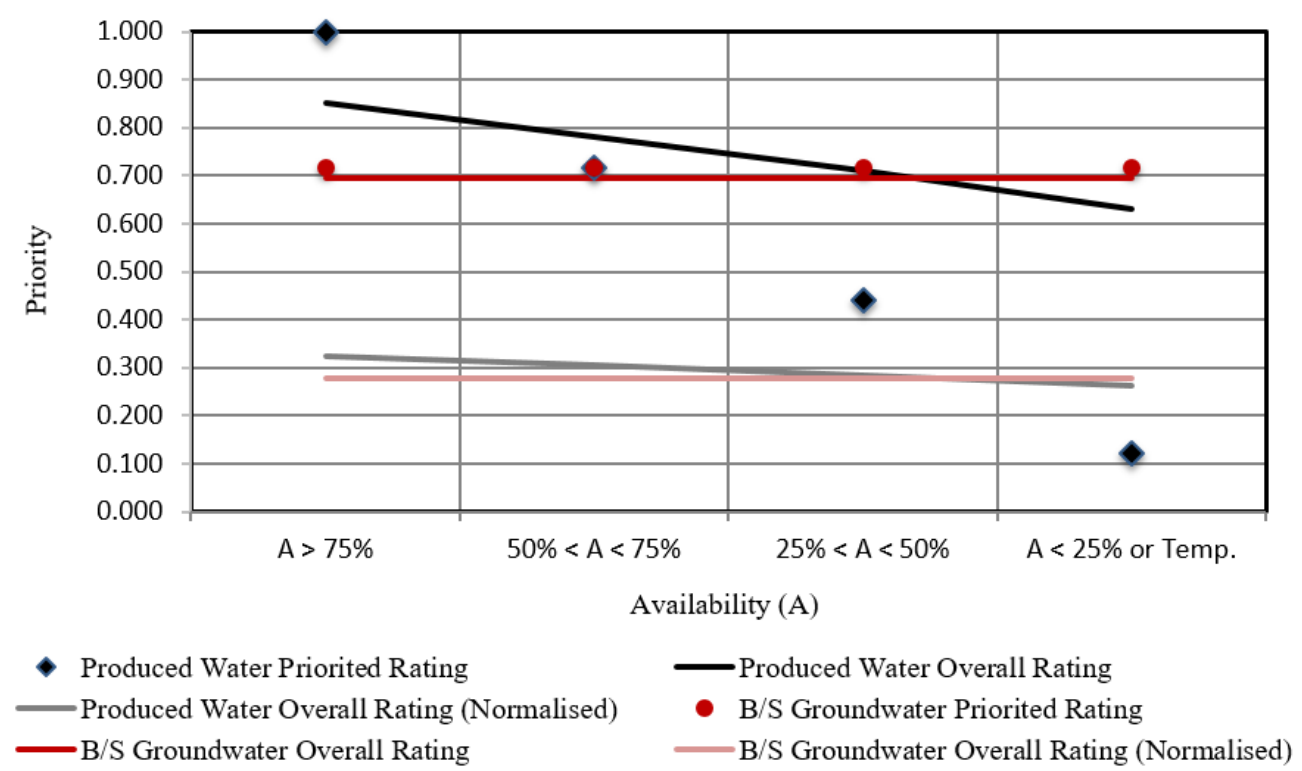

Figure 8: Sensitivity analysis for produced water and brackish/saline groundwater.

The sensitivity analysis graph in Figure 9 shows that consideration should only be given to changing the water source to brackish/saline groundwater if produced water availability falls below $25 \%$. Otherwise, produced water is the most appropriate source of water. Regardless of selection, produced, saline, and brackish water all require a fresh water source. Therefore, the optimal solution comprises a combination of two sources, which are produced water and fresh groundwater, for the Beetaloo Basin. 
Checking the consistency of decisions is part of the AHP process, and a consistency index and a ratio are used to reduce bias during the allocation of priorities in the pairwise comparisons. However, incorporating the contributions of multiple stakeholders with different perspectives is recommended, particularly when factors such as social and environmental issues based on subjective judgments are required.

A sensitivity analysis can also be used to further investigate which alternative is most convenient when priorities are similar or close to each other. Uncertain or subjective factors should be the first variables analysed, and the option with more benefits should be selected. In the Beetaloo Basin case study, reusing produced water was identified as the optimal water source option, but this comes with two critical variables that have a high level of uncertainty and may affect the results of the decision-making process. The two variables are the quality of the produced water and the volume of flowback water. Both are dependent on the geological characteristics of the shale formation, and sufficient information is not yet available. In conducting the sensitivity analysis, the brackish/saline water alternative was only found to be the better choice in one instance. This finding ultimately assisted in corroborating that the best alternative had been selected.

The application of system dynamics modelling for water management in shale gas developments shows that there are numerous variables that can be modified to achieve technical, economic, social, and environmental balance. However, petroleum companies and other stakeholders should concentrate on adjusting controllable variables to compensate for uncontrollable variables that produce undesirable events. In the case of Beetaloo Basin, and for the majority of shale developments, there are major uncontrollable variables that significantly affect the overall system. Here, the aquifer recharge rate for freshwater generation is dependent on rainfall intensity during the monsoon season. The quality of produced water and the quantity of flowback water are dependent on the geological characteristics of the shale formation. Those two variables, climate and geology, are uncontrollable and present a challenge when they generate a negative impact on the system. Consequently, other controllable variables are adjusted to compensate for these changes and maintain the balance. As an example, petroleum companies could anticipate and adjust their yearly operational program in the event of an extended dry season or diminished rainfall during the wet season to better manage fresh water shortages in the region, while still accommodating the water requirements of drilling and hydraulic fracturing simply by modifying a key variable in the system, such as hydraulic fracturing water intensity. Even if that results in reduced natural gas production or a delay in development time, but stakeholder support and public acceptance would be preserved. 
Petroleum companies must identify the optimal values of the controllable key variables, given limitations and risks, to improve the efficiency of water management. Although maximising the quantity of natural gas extraction is a priority for oil and gas operators, the other social and environmental factors have to be taken into consideration. Determining the optimal volume of water per stage of hydraulic fracturing is particularly critical because reducing the consumption of this type of water significantly affects the stability of the system. Excessive injection of fracture fluid may increase production, but the increases are not proportional, and doing this will have repercussions in the community and for the environment that generate public backlash and further problems with the long-term development.

\section{Conclusion and Future Work}

The development of shale gas resources in Australia demands the appropriate withdrawal, transportation, storage, use, and treatment of water from different sources to obtain stakeholder support and public acceptance. The core components of water management for shale gas development must be considered to sustainably exploit these unconventional resources, particularly in areas with limited fresh water. The combinatorial methodology presented in this paper uses MCDM and system dynamics to consider these issues and achieve a technical, economic, social, and environmental balance between all factors, while AHP is used to determine the most appropriate water sources in a region of study. The avoidance of fresh water over-extraction, the produced water reutilisation and the prevention of aquifer disturbance are approached by applying system dynamics modelling to identify and adjust key variables in the system to adapt to different circumstances and maintain the desired balance to ultimately obtain public acceptance. The performance of the proposed methodology is presented through the case study of the Beetaloo Basin, Northern Territory, Australia.

In future studies, we will examine the use of other MCDM techniques along with any new data that may become available for the selected basin. In addition, a more complex stock flow diagram that includes variables for rating attained levels of economic, social, and environmental factors will be developed.

\section{References}

Bala, B.K., Arshad, F.M. \& Noh, K.M. 2016, System Dynamics: Modelling and Simulation, Springer.

Cavana, R. \& Maani, K. 2000, 'A methodological framework for integrating systems thinking and system dynamics', Proceedings of the 18th International Conference of the System Dynamics Society, pp. 6-10.

Cook, P., Beck, V., Brereton, D., Clark, R., Fisher, B., Kentish, S., Toomey, J. \& Williams, J. 2013, 'Engineering energy: unconventional gas production: a study of shale gas in Australia'.

DENR, 2015, 'Northern Territory Water Allocation Planning Framework', Northern Territory Department of Environment and Natural Resources, Northern Territory Government, Darwin <http://denr.nt.gov.au/_data/assets/pdf_filr/0006/396717/ Water-Allocation-Framework.pdf>.

DOE, U. 2009, 'Modern shale gas development in the United States: A primer', Office of Fossil Energy and National Energy Technology Laboratory, United States Department of Energy. 
Erkine, W. 2003, Recommended environmental water requirements for the Daly River, Northern Territory, based on ecological, hydrological and biological principles, Supervising Scientist Darwin (NT).

Fast, J.C. \& Looper, L.T. 1988, Multiattribute Decision Modeling Techniques: A Comparative Analysis, METRICA INC SAN ANTONIO TX.

Fulton, S. \& Knapton, A. 2015, 'Beetaloo Basin Hydrogeological Assessment Report', Report from CloudGSM for Origin Energy, Darwin.

Gao, J. \& You, F. 2014, 'Optimization of water management in shale gas production process', Decision and Control (CDC), 2014 IEEE 53rd Annual Conference on, IEEE, pp. 6807-12.

Geoscience Australia, 2016, 'Australia Energy Resource Assessment', Geoscience Australia, Canberra <http://www.ga.gov.au/aera/gas>

Goldstein, B., Menpes, S., Hill, A., Wickham, A., Alexander, E., Jarosz, M., Pepicelli, D., Malavazos, M., Staritski, K. \& Taliangis, P. 2012, 'Roadmap for Unconventional Gas Projects in South Australia. South Australia Department for Manufacturing, Innovation, Trade', Resources and Energy, Energy Resources Division http://www. statedevelopment. sa. gov. au/resources/unconventional-gas-projects.

Hart, B., Jones, D., Coram, J., Smith, R., Priestly, B., McCabe, P., Andersen, A., Beck, V., Ashworth, P., \& Ritchie, D. 2017, 'Interim Report', Scientific Inquiry into Hydraulic Fracturing in the Northern Territory, Northern Territory Government, Darwin <https://frackinginquiry.nt.gov.au/>

Horner, R., Harto, C.B., Jackson, R.B., Lowry, E.R., Brandt, A.R., Yeskoo, T., Murphy, D.J. \& Clark, C.E. 2016, 'Water use and management in the Bakken shale oil play in North Dakota', Environmental science \& technology, vol. 50, no. 6, pp. 3275-82.

Ishizaka, A. \& Nemery, P. 2013, Multi-criteria decision analysis: methods and software, John Wiley \& Sons.

Jaber, J.O. \& Mohsen, M.S. 2001, 'Evaluation of non-conventional water resources supply in Jordan', Desalination, vol. 136, no. 1, pp. 83-92.

Jenkins, C.D. \& Boyer, C.M. 2008, 'Coalbed-and shale-gas reservoirs', Journal of Petroleum Technology, vol. 60, no. 02 , pp. $92-9$.

Linkov, I. \& Moberg, E. 2011, Multi-criteria decision analysis: environmental applications and case studies, CRC Press.

Munier, N. 2011, A strategy for using multicriteria analysis in decision-making: a guide for simple and complex environmental projects, Springer Science \& Business Media.

Nevill, J.C., Hancock, P.J., Murray, B.R., Ponder, W.F., Humphreys, W.F., Phillips, M.L. \& Groom, P.K. 2010, 'Groundwater-dependent ecosystems and the dangers of groundwater overdraft: a review and an Australian perspective', Pacific Conservation Biology, vol. 16, no. 3, pp. 187-208.

Nicot, J.-P. \& Scanlon, B.R. 2012, 'Water use for shale-gas production in Texas, US', Environmental science \& technology, vol. 46, no. 6, pp. 3580-6.

Okeola, O. \& Sule, B. 2012, 'Evaluation of management alternatives for urban water supply system using Multicriteria Decision Analysis', Journal of King Saud University-Engineering Sciences, vol. 24, no. 1, pp. 19-24.

Park, S., Jeon, D.-H. \& Jung, S.-Y. 2014, 'Developing efficient management strategies for a water supply system using system dynamics modelling', Civil Engineering and Environmental Systems, vol. 31, no. 3, pp. 189-208.

Rahm, B.G. \& Riha, S.J. 2012, 'Toward strategic management of shale gas development: Regional, collective impacts on water resources', Environmental Science \& Policy, vol. 17, pp. 12-23.

Saaty, T.L. 2008, 'Decision making with the analytic hierarchy process', International Journal of Services Sciences, vol. 1, no. 1, pp. 83-98.

Soeder, D.J. \& Kappel, W.M. 2009, Water resources and natural gas production from the Marcellus Shale, US Department of the Interior, US Geological Survey Reston, Virginia.

Speight, J.G. 2013, Shale gas production processes, Gulf Professional Publishing.

Stark, M. \& Thompson, P. 2013, 'Water Use in Shale Gas Developments', Disruptive Science and Technology, vol. 1, no. 4, pp. 164-8.

Sušnik, J., Vamvakeridou-Lyroudia, L.S., Savić, D.A. \& Kapelan, Z. 2012, 'Integrated System Dynamics Modelling for water scarcity assessment: Case study of the Kairouan region', Science of the total environment, vol. 440, pp. 290-306.

Velasquez, M. \& Hester, P.T. 2013, 'An analysis of multi-criteria decision making methods', International Journal of Operations Research, vol. 10, no. 2, pp. 56-66.

Ventana Systems Inc. 2017, Vensim Software, viewed 31 October 2017, <http://vensim.com/vensim-software/>

Vidic, R.D., Brantley, S.L., Vandenbossche, J.M., Yoxtheimer, D. \& Abad, J.D. 2013, 'Impact of shale gas development on regional water quality', Science, vol. 340, no. 6134, p. 1235009.

Warner, D. 2011, 'Shale gas in Australia: a great opportunity comes with significant challenges', Preview, vol. 2011, no. 155, pp. 18-21. 
Winz, I., Brierley, G. \& Trowsdale, S. 2009, 'The use of system dynamics simulation in water resources management', Water resources management, vol. 23, no. 7, pp. 1301-23.

Yang, L., Grossmann, I.E. \& Manno, J. 2014, 'Optimization models for shale gas water management', AIChE Journal, vol. 60, no. 10, pp. 3490-501.

Zarghami, M. \& Szidarovszky, F. 2011, Multicriteria analysis: applications to water and environment management, Springer Science \& Business Media.

Cavana, R. \& Maani, K. (2000). A methodological framework for integrating systems thinking and system dynamics. In: Proceedings of the 18th International Conference of the System Dynamics Society (pp. 610).

Cook, P., Beck, V., Brereton, D., Clark, R., Fisher, B., Kentish, S., Toomey, J. \& Williams, J. (2013). Engineering energy: unconventional gas production: a study of shale gas in Australia.

DOE, U. (2009). Modern shale gas development in the United States: A primer. Office of Fossil Energy and National Energy Technology Laboratory, United States Department of Energy.

Gao, J. \& You, F. (2014). Optimization of water management in shale gas production process. In: Decision and Control (CDC), 2014 IEEE 53rd Annual Conference on (pp. 6807-6812): IEEE.

Goldstein, B., Menpes, S., Hill, A., Wickham, A., Alexander, E., Jarosz, M., Pepicelli, D., Malavazos, M., Staritski, K. \& Taliangis, P. (2012). Roadmap for Unconventional Gas Projects in South Australia. South Australia Department for Manufacturing, Innovation, Trade. Resources and Energy, Energy Resources Division http://www. statedevelopment. sa. gov. au/resources/unconventional-gas-projects.

Horner, R., Harto, C.B., Jackson, R.B., Lowry, E.R., Brandt, A.R., Yeskoo, T., Murphy, D.J. \& Clark, C.E. (2016). Water use and management in the Bakken shale oil play in North Dakota. Environmental science \& technology, 50(6), 3275-3282.

Jasmin, C., Laurence, S. \& Adisa, A. (2016). Shale Gas: A Review of the Economic, Environmental, and Social Sustainability. Energy Technology, 4(7), 772-792.

Jenkins, C.D. \& Boyer, C.M. (2008). Coalbed-and shale-gas reservoirs. Journal of Petroleum Technology, 60(02), 92-99.

Linkov, I. \& Moberg, E. (2011). Multi-criteria decision analysis: environmental applications and case studies: CRC Press.

Nicot, J.-P. \& Scanlon, B.R. (2012). Water use for shale-gas production in Texas, US. Environmental science \& technology, 46(6), 3580-3586.

Pruyt, E. (2013). Small System Dynamics Models for Big Issues: Triple Jump towards Real-World Dynamic Complexity.

Rahm, B.G. \& Riha, S.J. (2012). Toward strategic management of shale gas development: Regional, collective impacts on water resources. Environmental Science \& Policy, 17, 12-23.

Saaty, T.L. (2008). Decision making with the analytic hierarchy process. International journal of services sciences, 1(1), 83-98.

Soeder, D.J. \& Kappel, W.M. (2009). Water resources and natural gas production from the Marcellus Shale: US Department of the Interior, US Geological Survey Reston, Virginia.

Speight, J.G. (2013). Shale gas production processes: Gulf Professional Publishing.

Stark, M. \& Thompson, P. (2013). Water Use in Shale Gas Developments. Disruptive Science and Technology, 1(4), 164-168.

Vidic, R.D., Brantley, S.L., Vandenbossche, J.M., Yoxtheimer, D. \& Abad, J.D. (2013). Impact of shale gas development on regional water quality. Science, 340(6134), 1235009.

Wang, J.-J., Jing, Y.-Y., Zhang, C.-F. \& Zhao, J.-H. (2009). Review on multi-criteria decision analysis aid in sustainable energy decision-making. Renewable and Sustainable Energy Reviews, 13(9), 2263-2278.

Warner, D. (2011). Shale gas in Australia: a great opportunity comes with significant challenges. Preview, 2011(155), 18-21.

Winz, I., Brierley, G. \& Trowsdale, S. (2009). The use of system dynamics simulation in water resources management. Water resources management, 23(7), 1301-1323.

Yang, L., Grossmann, I.E. \& Manno, J. (2014). Optimization models for shale gas water management. AIChE Journal, 60(10), 3490-3501.

Zarghami, M. \& Szidarovszky, F. (2011). Multicriteria analysis: applications to water and environment management: Springer Science \& Business Media. 